\title{
openheart A decade of changes in clinical characteristics and management of elderly patients with non-ST elevation myocardial infarction admitted in Italian cardiac care units
}

\author{
Leonardo De Luca, ${ }^{1}$ Zoran Olivari, ${ }^{2}$ Leonardo Bolognese, ${ }^{3}$ Donata Lucci, ${ }^{4}$ \\ Lucio Gonzini, ${ }^{4}$ Antonio Di Chiara, ${ }^{5}$ Gianni Casella, ${ }^{6}$ Francesco Chiarella, ${ }^{7}$ \\ Alessandro Boccanelli, ${ }^{8}$ Giuseppe Di Pasquale, ${ }^{6}$ Francesco M Bovenzi, ${ }^{9}$ \\ Stefano Savonitto ${ }^{10}$
}

To cite: De Luca L, Olivari Z, Bolognese $\mathrm{L}$, et al. A decade of changes in clinical characteristics and management of elderly patients with non-ST elevation myocardial infarction admitted in Italian cardiac care units. Open Heart 2014;1:e000148. doi:10.1136/openhrt-2014000148

Received 16 May 2014 Revised 24 July 2014 Accepted 4 November 2014

CrossMark

For numbered affiliations see end of article.

Correspondence to Dr Stefano Savonitto; s.savonitto@ospedale.lecco.it

\section{ABSTRACT}

Objective: To describe the evolution of clinical characteristics, in-hospital management and early outcome of elderly patients with non-ST elevation myocardial infarction (NSTEMI).

Methods: We analysed data from five consecutive Italian nationwide registries, conducted between 2001 and 2010, including patients with acute coronary syndromes admitted to cardiac care units (CCUs).

Results: Of 10983 patients with NSTEMI enrolled in the 5 surveys, $4350(39.6 \%)$ were $\geq 75$ years old (mean age $81 \pm 5$ years). Some clinical characteristics such as diabetes mellitus, hypertension, renal dysfunction and previous percutaneous coronary intervention increased significantly, whereas a history of stroke, myocardial infarction and heart failure decreased over time. An invasive approach increased from $26.6 \%$ in 2001 to $68.4 \%$ in $2010(p<0.0001)$ and revascularisation rates increased from $9.9 \%$ to $51.7 \%$ $(p<0.0001)$. Early use and prescription at discharge of $\beta$-blockers, statins and dual antiplatelet treatment increased significantly $(p<0.0001)$. Thirty-day observed mortality decreased from $14.6 \%(95 \% \mathrm{Cl} 9.9$ to 20.4$)$ to $9.5 \%(95 \% \mathrm{Cl} 7.7$ to 11.6$)$. At the multivariate logistic regression analyses adjusted for baseline characteristics, compared with 2001, the risk of death was significantly lower in all the other studies performed at different times with reductions in adjusted mortality between $66 \%$ and $45 \%$.

Conclusions: Over the past decade, substantial changes have occurred in the clinical characteristics and management of elderly patients admitted with NSTEMI in Italian CCUs, with a greater use of revascularisation therapy and recommended medications. These variations have been associated with a reduction in 30-day adjusted mortality rate.

\section{INTRODUCTION}

The management of patients with acute coronary syndromes (ACS) has evolved over the

\section{KEY QUESTIONS}

What is already known about this subject?

- The elderly are a subgroup known to be at high risk; they are under-represented in guidelinegenerating clinical trials, and real-world registries continue to demonstrate less use of cardiac medications and invasive care, even among those who are likely to derive benefit.

What does this study add?

- We demonstrated that substantial changes occurred in the clinical characteristics and management of elderly patients admitted with a diagnosis of NSTEMI over the past decade. These changes have been associated with a reduction in the adjusted early mortality rate.

How might this impact on clinical practice?

- These data might encourage the use of recommended interventional and pharmacological strategies, including anti-thrombotic drugs during hospitalisation and life-saving therapies prescribed at discharge, in this high-risk population.

past decade with the development of new therapeutics and strategies of care that have been shown to improve outcomes in clinical trials. ${ }^{1}{ }^{2}$ However, the extent to which this new evidence is applied in clinical practice and whether such changes are associated with favourable outcomes requires continuous assessment, particularly in patients scarcely represented in large randomised studies. The elderly are a subgroup known to be at high risk; they are under-represented in guidelinegenerating clinical trials, and real-world registries continue to demonstrate less use of cardiac medications and invasive care, even among those who are likely to derive benefit. ${ }^{3}$ Within the whole spectrum of ACS, 
older patients admitted to cardiac care units (CCUs) present more frequently without ST-segment elevation ${ }^{3-6}$ and especially those with elevated biomarkers on admission seem to benefit from early invasive management. ${ }^{78}$

The aim of the present study was to describe the evolution of clinical characteristics, in-hospital management and early mortality of elderly patients admitted to CCUs with a diagnosis of non-ST elevation myocardial infarction (NSTEMI) by analysing data from nationwide Italian registries conducted between 2001 and 2010.

\section{METHODS}

Five consecutive nationwide registries designed by the Italian Hospital Cardiology Association (ANMCO) on patients with ACS were conducted in Italy between 2001 and 2010: BLITZ in 2001, ${ }^{9}$ BLITZ-2 in $2003,{ }^{10}$ IN-ACS OUTCOME (Italian Network on Acute Coronary Syndromes Outcome) in 2006-2007, ${ }^{11}$ BLITZ-4 in 2009 and $2010^{12}$ and MANTRA (Management of patients with ACS in the real-world practice in Italy: an outcome research study focused on the use of ANTithRombotic Agents) in 2009-2010. ${ }^{13}$ All surveys included patients with ACS consecutively admitted alive to the participating CCUs during a prespecified period (few weeks for the BLITZ registries and 1 year for the IN-ACS OUTCOME and MANTRA registries; table 1). The methods used for each registry have been described previously. ${ }^{9-13}$ Briefly, their primary objectives were to evaluate the characteristics, management and outcomes of consecutive patients with ACS admitted to Italian CCUs, using a catchment broad enough to provide data representative of the entire country. Participation in the study was offered to all institutions, including university teaching hospitals, general and regional hospitals, and private clinics with CCUs receiving patients with ACS. Physicians were instructed that participation in the study should not affect clinical care or management.

All patients were informed of the nature and aims of the surveys and were asked to sign an informed consent form for the anonymous management of their individual data. Local Institutional Review Boards were informed of the study, according to the Italian rules.

For the present analysis, only patients aged $\geq 75$ years presenting with elevated troponin and/or creatine kinase (CK)-MB fraction levels, and without persistent ST segment elevation and/or new onset $Q$ waves or leftbundle branch block, were considered.

\section{Data collection}

Data on baseline characteristics including demographics, risk factors and medical history were collected as previously described. ${ }^{9-13}$ Information on the use of cardiac procedures, including coronary angiography, type and timing of revascularisation therapy (if any), use of medications during hospitalisation and at hospital discharge, and in-hospital major clinical events, were recorded. In all surveys, clinical events were also assessed at 30 days.

Clinical reinfarction during initial hospitalisation was diagnosed in the presence of new ischaemic symptoms and a re-elevation of biochemical myocardial necrosis markers with or without concurrent ECG changes. In all studies, major bleeding was classified according to the

Table 1 Characteristics of the 5 Italian Surveys

\begin{tabular}{|c|c|c|c|c|c|c|}
\hline Study & $\begin{array}{l}\text { Enrolment } \\
\text { period }\end{array}$ & $\begin{array}{l}\text { Number of } \\
\text { participating } \\
\text { centres }\end{array}$ & $\begin{array}{l}\text { Percentage of } \\
\text { centres with } \\
\text { catheterisation } \\
\text { laboratory }\end{array}$ & $\begin{array}{l}\text { Target } \\
\text { population }\end{array}$ & $\begin{array}{l}\text { Number of } \\
\text { patients with } \\
\text { NSTEMI } \\
\text { enrolled }\end{array}$ & $\begin{array}{l}\text { Percentage of } \\
\text { patients with } \\
\text { NSTEMI } \\
\geq 75 \text { years old }\end{array}$ \\
\hline BLITZ & $\begin{array}{l}15-29 \text { October } \\
2001\end{array}$ & 296 & 44.6 & $\begin{array}{l}\text { Consecutive } \\
\text { patients with } \\
\text { STEMI and } \\
\text { NSTEMI }\end{array}$ & 580 & 33.1 \\
\hline BLITZ-2 & 6-27 May 2003 & 275 & 41.2 & $\begin{array}{l}\text { Consecutive } \\
\text { patients with } \\
\text { NSTEACS }\end{array}$ & 1059 & 32.8 \\
\hline $\begin{array}{l}\text { IN-ACS } \\
\text { OUTCOME }\end{array}$ & $\begin{array}{l}2 \text { December } \\
2005-8 \text { February } \\
2008\end{array}$ & 38 & 47.4 & $\begin{array}{l}\text { Consecutive } \\
\text { patients with } \\
\text { ACS }\end{array}$ & 2327 & 39.7 \\
\hline BLITZ-4 & $\begin{array}{l}15 \text { September- } \\
30 \text { November } \\
2009 \text { and } 15 \\
\text { February-30 } \\
\text { April } 2010\end{array}$ & 163 & 83.0 & $\begin{array}{l}\text { Consecutive } \\
\text { patients with } \\
\text { ACS }\end{array}$ & 4511 & 43.0 \\
\hline MANTRA & $\begin{array}{l}22 \text { April 2009-29 } \\
\text { December } 2010\end{array}$ & 52 & 65.4 & $\begin{array}{l}\text { Consecutive } \\
\text { patients with } \\
\text { ACS }\end{array}$ & 2506 & 37.8 \\
\hline
\end{tabular}

ACS, acute coronary syndrome; CCUs, cardiac care units; NSTEACS, non-ST elevation ACS; NSTEMI, non-ST elevation myocardial infarction; STEMI, ST elevation myocardial infarction. 
thrombolysis in MI (TIMI) criteria. ${ }^{14}$ Heart failure was defined as the presence of signs and/or symptoms of pulmonary congestion in the absence of a non-cardiac cause. Stroke was identified as an acute neurological deficit that lasted $>24 \mathrm{~h}$ and affected the ability to perform daily activities with or without confirmation by imaging techniques.

All data were collected using a case report form at the participating centres and entered in a centralised database located at the ANMCO Research Center in Florence. By using a validation plan, integrated in the data entry software, data were checked for missing or contradictory entries and values out of the normal range.

\section{Statistical analysis}

Categorical variables were reported as percentages and compared by $\chi^{2}$ test, whereas continuous variables were reported as means and SDs and compared by analysis of variance, if normally distributed, or by the Kruskal-Wallis test, if not. Temporal trends were tested using the Cochran-Armitage test for binary variables and the Kendall Tau rank correlation coefficient with the Jonckheere-Terpstra test for continuous variables. The $95 \%$ CIs of the difference of percentage changes were evaluated using the $\mathrm{R}$ package proCIs. Since the baseline patient characteristics showed significant changes in the five registries, we calculated a risk score for the 2010 MANTRA population using a logistic regression model resulting statistically significant at univariate analysis or considered of clinical interest. These variables included gender, age, diabetes, history of heart failure, prior stroke/transient ischaemic attacks (TIA), peripheral vascular disease, prior renal failure, systolic blood pressure, heart rate, Killip class and atrial fibrillation at admission. This score, evaluated on the 2010 MANTRA population, was also used to standardise the death rates for each of the previous surveys. The standardised death rates therefore represent the rates that would have been expected if the distribution of the baseline characteristics of each of the first four surveys had been similar to that of the most recent one.

Finally, a multivariate analysis (logistic model) was conducted to identify the independent predictors of use of coronary angiography during index hospitalisation; variables statistically significant at univariate analysis were also inserted in the model: gender, age, smoking habits, prior acute myocardial infarction (AMI), prior revascularisation, history of heart failure, prior stroke/ TIA, prior renal failure, systolic blood pressure, heart rate, Killip class and atrial fibrillation at entry, admission to a hospital with catheterisation laboratory facilities, as well as study cohort (2001 as referral).

All tests were two-sided; a $p$ value $<0.05$ was considered statistically significant. All analyses were conducted with SAS system software V.9.2 and with the ' $R$ ' Development Core Team 2012.

\section{RESULTS}

\section{Baseline characteristics}

Of the 10983 patients with NSTEMI enrolled in the five surveys, $4350(39.6 \%)$ were $\geq 75$ years old. The percentages of these patients enrolled in the individual studies are reported in table 1 . The mean age of the populations included in the analysis was similar ( $p$ for trend $=0.74$ ). During this 10-year period, the rates of elderly patients with prior cerebrovascular accidents, history of angina, myocardial infarction (MI) and heart failure declined, whereas the proportions of patients with diabetes mellitus, hypertension, renal dysfunction, previous percutaneous coronary intervention (PCI) and on $\beta$-blocker and statin therapy significantly increased (table 2 ).

\section{Hospital management}

The percentage of patients admitted to hospitals with catheterisation laboratory facilities increased substantially from $48 \%$ in 2001 to $71 \%$ in 2010 (percentage change 23 (95\% CI 15 to 30)) and those undergoing coronary angiography at any time during index admission increased from $27 \%$ in 2001 to $68 \%$ in 2010 (percentage change, 42 (95\% CI 35 to 48); figure 1), with a significant reduction in the time delay from hospital admission to angiography (figure 2). During the whole 10 -year period, an invasive strategy was adopted in $74 \%$ of the patients admitted to hospitals with a catheterisation laboratory versus $42 \%$ of those admitted to hospitals without catheterisation laboratory $(\mathrm{p}<0.0001)$. At multivariate analysis, the presence of catheterisation laboratory was the strongest independent predictor of use of coronary angiography, followed by the year of the registry (the most recent being associated with higher probability). On the other hand, older age, haemodynamic deterioration (as identified by blood pressure, heart rate and Killip class), chronic kidney dysfunction and female gender were the strongest negative predictors of coronary angiography (figure 3 ).

Accordingly, the use of revascularisation therapy increased from $9.9 \%$ to $51.7 \%$ (percentage change from 2001 to $2010,42(95 \%$ CI 36 to 47$)$ ), with a more frequent use of PCI (9.4\% to $47 \%$; percentage change, 37 (95\% CI 31 to 42 )) and coronary artery bypass grafting (CABG; 0.5-5.6\%; percentage change, 5.1 (95\% CI 2.5 to 6.9 ); figure 1). In general, among patients who underwent coronary angiography, myocardial revascularisation (PCI or CABG) was performed in $37 \%$ in $2001,55 \%$ in $2003,68 \%$ in 2006 and $75 \%$ in 2010 ( $\mathrm{p}$ for trend $<0.0001$; percentage change from 2001 to 2010,38 (95\% CI 24 to 51)).

Antithrombotic medications used during hospitalisation changed markedly with increasing use of dual antiplatelet therapy from $17 \%$ in 2001 to $85 \%$ in 2010 ( $\mathrm{p}$ for trend $<0.0001$; percentage change, 68 (95\% CI 62 to 73$)$ ) and fondaparinux (15\% in 2009 and $21 \%$ in 2010, $\mathrm{p}<0.0001$; figure 4). On the other hand, the use of low-molecular-weight heparins (from 66\% in 2001 to $48 \%$ in 2010 , percentage change, -19 (95\% CI -26 
Table 2 Baseline characteristics of elderly patients with NSTEMI from 2001 to 2010

\begin{tabular}{|c|c|c|c|c|c|c|}
\hline & $\begin{array}{l}\text { BLITZ, } \\
2001 \\
n=192\end{array}$ & $\begin{array}{l}\text { BLITZ-2, } \\
2003 \\
n=347\end{array}$ & $\begin{array}{l}\text { IN-ACS } \\
\text { OUTCOME, } \\
2006-2007 \\
n=923\end{array}$ & $\begin{array}{l}\text { BLITZ-4, } \\
2009 \& 2010 \\
n=1941\end{array}$ & $\begin{array}{l}\text { MANTRA, } \\
2009-2010 \\
n=947\end{array}$ & $\begin{array}{l}p \text { for } \\
\text { trend }\end{array}$ \\
\hline Age, years (mean $\pm S D)$ & $81 \pm 5$ & $81 \pm 5$ & $81 \pm 5$ & $82 \pm 5$ & $81 \pm 5$ & 0.74 \\
\hline Female, \% & 45.3 & 49.6 & 45.5 & 45.0 & 43.8 & 0.17 \\
\hline \multicolumn{7}{|l|}{ Risk factors and comorbidities, \% } \\
\hline Active smokers & 7.8 & 8.1 & 7.7 & 8.5 & 9.4 & 0.26 \\
\hline Dyslipidaemia & $\mathrm{n} / \mathrm{a}$ & 38.0 & 42.7 & 32.8 & 42.3 & 0.80 \\
\hline Diabetes mellitus & 24.5 & 32.0 & 29.3 & 35.2 & 36.1 & $<0.0001$ \\
\hline Hypertension & 69.8 & 71.8 & 70.7 & 76.6 & 77.4 & 0.0001 \\
\hline Renal dysfunction & 8.3 & 13.0 & 16.4 & 20.6 & 21.2 & $<0.0001$ \\
\hline \multicolumn{7}{|l|}{ Cardiovascular history, \% } \\
\hline Peripheral artery disease & 20.3 & 23.6 & 20.8 & 17.5 & 20.0 & 0.11 \\
\hline Previous stroke/TIA & 16.7 & 18.4 & 11.2 & 8.7 & 10.4 & $<0.0001$ \\
\hline History of angina & 42.7 & 23.0 & 23.7 & 25.5 & 17.4 & $<0.0001$ \\
\hline Heart failure & 16.7 & 11.5 & 8.1 & 7.0 & 8.8 & 0.001 \\
\hline Previous MI & 32.8 & 39.4 & 30.8 & 19.1 & 27.3 & $<0.0001$ \\
\hline Previous PCl & 6.3 & 9.6 & 11.6 & 16.4 & 17.0 & $<0.0001$ \\
\hline Previous CABG & 6.8 & 7.4 & 8.7 & 9.5 & 9.8 & 0.08 \\
\hline \multicolumn{7}{|l|}{ Variables at admission } \\
\hline Killip class III-IV, \% & 17.7 & 13.0 & 10.4 & 11.5 & 11.5 & 0.12 \\
\hline $\mathrm{SBP}, \mathrm{mm} \mathrm{Hg}($ mean $\pm \mathrm{SD})$ & $143 \pm 30$ & $147 \pm 27$ & $142 \pm 28$ & $139 \pm 26$ & $140 \pm 28$ & 0.007 \\
\hline $\mathrm{HR}, \mathrm{bpm}($ mean $\pm \mathrm{SD})$ & $86 \pm 24$ & $84 \pm 22$ & $83 \pm 22$ & $82 \pm 19$ & $84 \pm 22$ & 0.68 \\
\hline Ejection fraction, \% (mean $\pm S D)$ & $52 \pm 12$ & $47 \pm 10$ & $47 \pm 11$ & $47 \pm 11$ & $48 \pm 11$ & 0.38 \\
\hline Atrial fibrillation, $\%$ & 16.2 & 13.0 & 12.2 & 13.2 & 12.0 & 0.34 \\
\hline ECG changes, \% & 100.0 & 88.2 & 63.4 & 73.8 & 73.4 & $<0.0001$ \\
\hline \multicolumn{7}{|l|}{ Medication before admission, \% } \\
\hline Antiplatelet agents & 45.3 & 57.6 & 54.0 & 54.2 & 55.2 & 0.24 \\
\hline Oral anticoagulant agents & 3.1 & 3.8 & 5.7 & 6.4 & 5.2 & 0.16 \\
\hline ACE-I/ARB & 44.8 & 49.6 & 53.7 & 58.4 & 52.7 & 0.01 \\
\hline$\beta$-blockers & 17.2 & 19.9 & 28.6 & 31.9 & 29.7 & $<0.0001$ \\
\hline Statins & 13.5 & 14.7 & 23.0 & 32.5 & 31.6 & $<0.0001$ \\
\hline
\end{tabular}

ACE-I/ARB, ACE inhibitors/angiotensin receptor blockers; CABG, coronary artery bypass grafting; CAD, coronary artery disease; HR, heart rate; MI, myocardial infarction; NSTEMI, non-ST elevation MI; PCI, percutaneous coronary intervention; SBP, systolic blood pressure; TIA, transient ischaemic attacks.

to -11$)$ ) decreased over the years. It is noteworthy that the use of unfractionated heparin (from $46 \%$ to $34 \%$, percentage change, $-12(95 \%$ CI -20 to -4.3$))$, oral anticoagulation therapy (from $8.3 \%$ to $4.3 \%$, percentage change, $-4.0(95 \%$ CI -8.9 to -0.5$))$ and intravenous glycoprotein IIb/IIIa inhibitors (from $14 \%$ to $17 \%$, percentage change, 3.1 (95\% CI -2.9 to 8.1$))$ did not change significantly (figure 4). At the time of the studies, the use of bivalirudin in NSTEMI was very limited in Italy $(0.6 \%$ in BLITZ 4,2009$)$.

The use of evidence-based treatments at discharge increased gradually over the 10 -year period. Dual antiplatelet treatment was prescribed in $9.3 \%$ of elderly patients discharged alive in 2001 and $75 \%$ in 2010 (percentage change, 66 (95\% CI 60 to 70$))$; $\beta$-blockers in $47 \%$ in 2001 and $71 \%$ in 2010 (percentage change, 24 (95\% CI 16 to 32$)$ ); and statins in $37 \%$ in 2001 and $82 \%$ in 2010 (percentage change, 45 (95\% CI 37 to 52); figure 5).

As shown in figure 2, the mean length of hospital stay decreased significantly over the 10-year period, and the percentage of patients directly discharged home decreased significantly from $87 \%$ in 2001 to $83 \%$ in 2003, 77\% in 2006, 72\% in 2009 and $78 \%$ in 2010 ( p for trend $=0.0006$; percentage change from 2001 to 2010, $-9.0(95 \%$ CI -2.6 to -14.2$))$ in favour of transfers to rehabilitation or other structures.

\section{Clinical outcomes}

The crude rates of in-hospital major clinical events, including death, heart failure, stroke and major bleeding, did not show a significant trend during the decade of analysis (table 3). However, the incidence of reinfarction (from $1.6 \%$ in 2001 to $3.0 \%$ in 2010 , percentage change, 1.4 (95\% CI -1.6 to 3.1$)$ ) showed an important difference between studies, though without a clear trend. At 30-day follow-up, the cumulative incidence of clinical events did not show any significant time trend over the 10-year period, despite remarkable differences in event rates between the studies (table 3).

Crude 30-day mortality decreased from $14.6 \%$ in 2001 to $9.5 \%$ in 2010 (percentage change, -5.1 (95\% CI 
Figure 1 In-hospital use of coronary angiography, percutaneous coronary intervention $(\mathrm{PCl})$, coronary artery bypass grafting (CABG) or coronary revascularisation (PCl/ CABG) from 2001 to 2010.

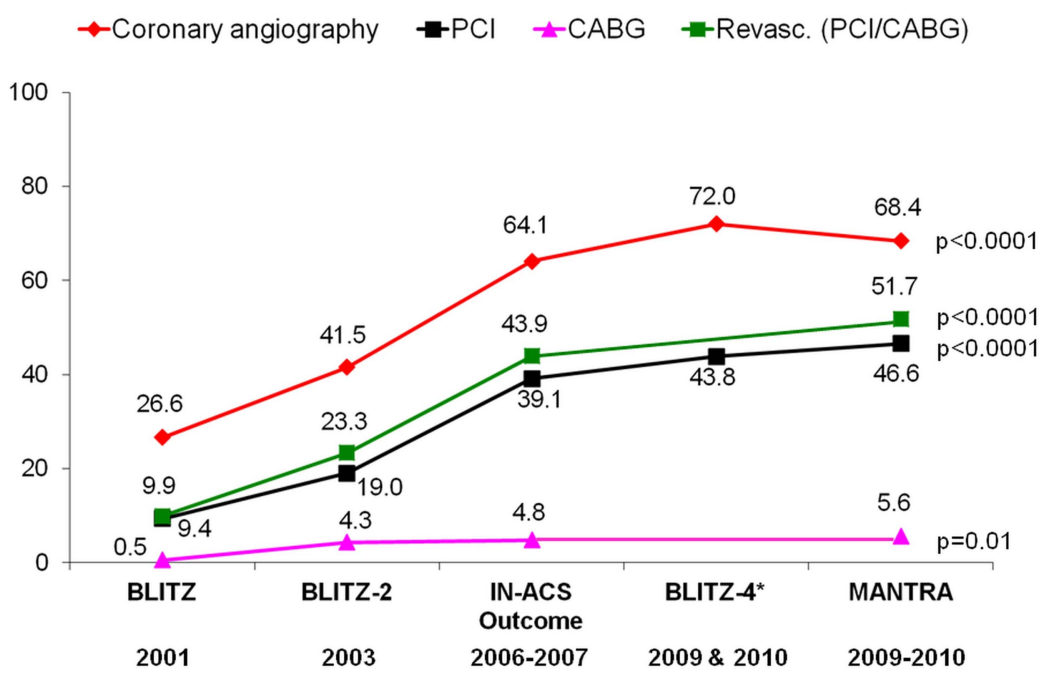

"In BLITZ-4, for patients tran sferred from enrolling hospitals with out interventional facilities to interventional centers, the rate of PCls is unknown. Consequently, the rate of PCls is reported only for non tran sferred patients $(82.9 \%)$; the rate of $\mathrm{ABG}$ referred to the indication and not to the execution of the procedure, therefore it has not been reported in the figure.
-11.0 to -0.3$))$, though without a statistically significant time trend $(p=0.36)$. As shown in figure 6 , when the death rates were standardised for the 2010 risk score (representing the expected rates, standardised on the risk distribution profile of 2010 MANTRA population), estimated mortality was fairly stable over time $18.9 \%$ in $2001,7.8 \%$ in $2003,8.8 \%$ in $2006,9.7 \%$ in 2009 and $9.5 \%$ in 2010), but these were quite different from the observed rates $(14.6 \%, 7.5 \%, 7.0 \%, 6.2 \%$ and $9.5 \%$, respectively). Moreover, after multivariate adjustments for the differences in baseline characteristics, the risk of death was significantly lower in all of the registries as compared to BLITZ, with reductions in adjusted mortality of between $66 \%$ (BLITZ-4) and $45 \%$ (MANTRA).

\section{DISCUSSION}

The main findings of this study are as follows: (1) elderly patients account for approximately $40 \%$ of the
NSTEMI population admitted to Italian CCUs and this proportion is increasing slightly over the years; (2) the clinical characteristics of elderly patients admitted to the CCUs in Italy have changed, with increasing rates of patients with diabetes, renal dysfunction and prior revascularisations; (3) the use of coronary angiography, myocardial revascularisation (mainly PCI) and adjunctive evidence-based therapies in this high-risk population has increased dramatically and (4) after adjustment for the changing baseline characteristics, these advances in care seem to be associated with a reduction in the rate of early mortality.

Although patients aged $\geq 75$ years represent up to $40 \%$ of CGU admissions with NSTEACS, they account for only $10 \%$ of patients enrolled in clinical trials. ${ }^{15}$ Moreover, elderly patients with ACS in the community are at a higher disease-related risk than those randomised in trials and have more comorbidities. ${ }^{15}$ Indeed, during the 10-year period of our analysis, the rate of
Figure 2 Mean delay between admission and coronary angiography; and mean length of hospital stay in the various studies between 2001 and 2010 .
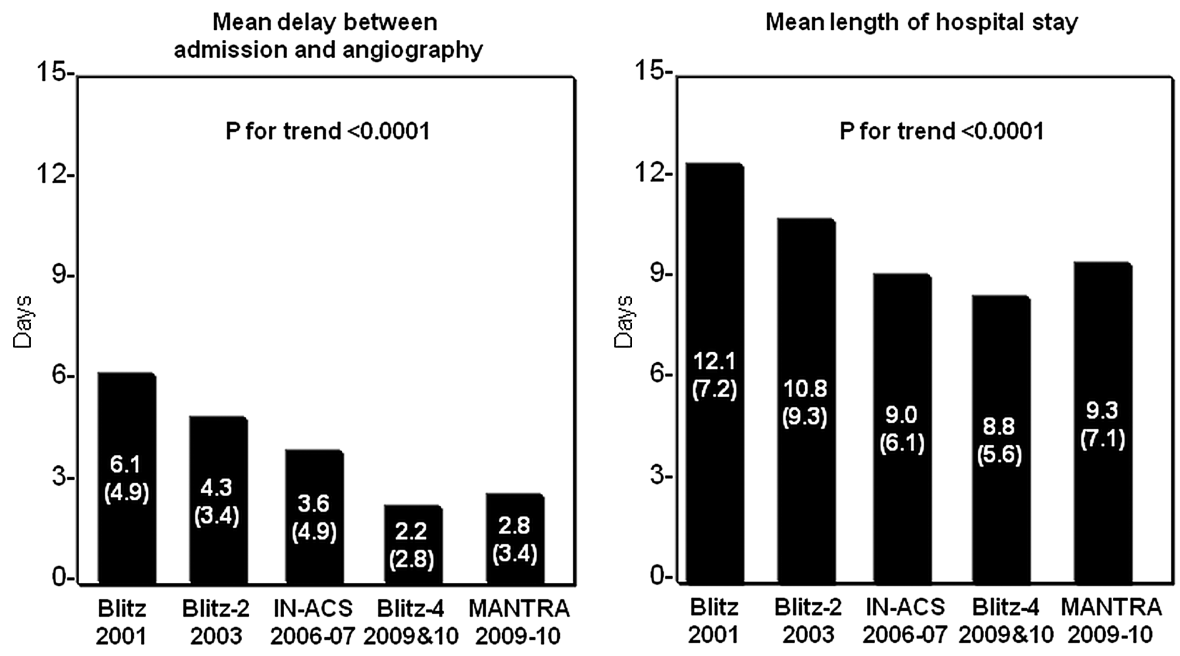


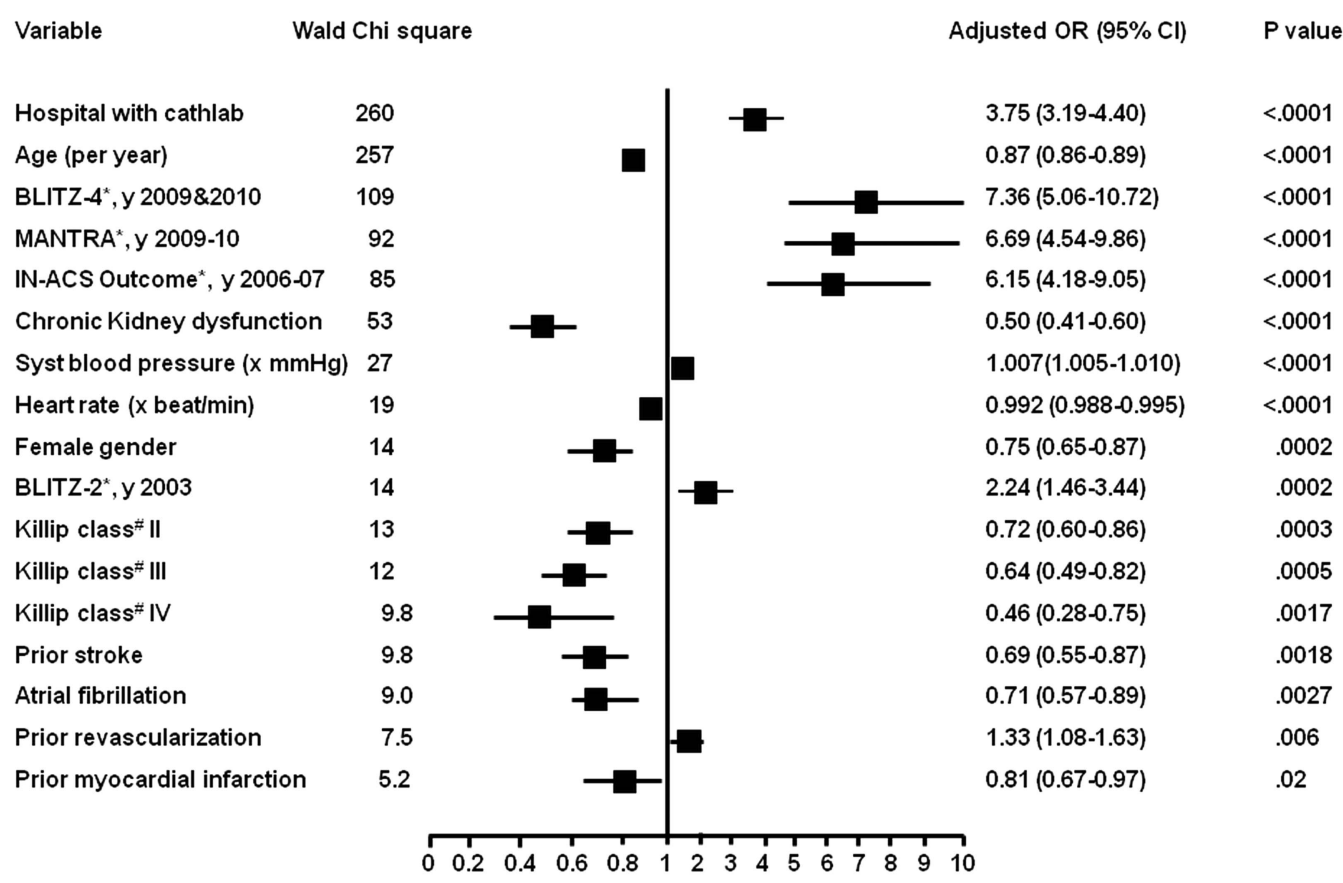

"As compared to the BLITZ Registry (year 2001). "As compared to Killip ClassI.

OR: adds ratio; $\mathrm{Cl}$ : confidence interval

Figure 3 Independent predictors of coronary angiography during index admission at logistic regression analysis.

elderly patients with traditional risk factors such as previous cerebrovascular accident, history of angina, MI and heart failure declined, suggesting more effective preventive strategies and/or favourable impact of previous revascularisations. On the other hand, the number of elderly patients with comorbidities such as diabetes mellitus and renal dysfunction increased consistently, suggesting a growing availability of the CCU cardiologist to treat this complex population aggressively.

Lack of randomised clinical trial data to guide acute care in elderly patients and in patients with comorbidities might explain the lower use of evidence-based therapies among elderly patients with ACS. ${ }^{3}{ }^{4}$ The Euro Heart survey, an international cohort study including patients with ACS from 25 European countries, showed that elderly patients were less intensively treated than younger patients and had a higher in-hospital mortality. ${ }^{4}$ Nevertheless, patients $\geq 75$ years old seem to benefit from potent adjunctive evidence-based therapies together with an early invasive approach, particularly those with ST elevation MI (STEMI) or NSTEACS with elevated biomarkers. ${ }^{76} 17$ In the Italian Elderly ACS study, the first randomised trial comparing treatment strategies in elderly patients with NSTEACS, patients with elevated troponin levels on admission randomised to an early aggressive approach had a significant $57 \%$ reduction in the rate of the primary end point (a composite of ischaemic and bleeding events) at 1 year. $^{7}$ In the present analysis, the remarkable increase over time in the use of life-saving pharmacological therapies, coronary angiography and PCI as revascularisation modality was not paralleled by a significant trend towards the reduction of 30-day mortality, which, however, became evident, and statistically highly significant after adjustment for other powerful predictors of death such as diabetes, chronic kidney dysfunction, ${ }^{18} 19$ and markers of ventricular dysfunction such as prior heart failure, low blood pressure, high baseline heart rate and Killip class.

A further possible explanation for comparable crude mortality rates recorded after the year 2003 is the shortterm follow-up available in our surveys. In another registry that showed a significant increase in the use of guidelines-recommended treatments including PCI among more than 900 elderly patients admitted for MI between 2000 and 2006, a difference in mortality at 1 month was evident in case of STEMI, whereas there was only a non-significant trend towards reduction in mortality in patients with NSTEMI, despite a fourfold increase in the rate of invasive strategy during index admission. ${ }^{20}$ Indeed, in the pivotal randomised clinical trials comparing an early invasive and an initially conservative treatment in NSTEACS, the clinical benefit in terms of death and/or MI after an invasive strategy in NSTEACS are usually observed after 6 months to 1 year of admission. ${ }^{81}$ This is particularly evident in some patient populations with ACS, such as the elderly, in whom most deaths have a cardiac ischaemic origin, and the higher risk rises from 30 days to 1 year, especially after revascularisation. ${ }^{22}$ Accordingly, the 5-year follow-up from the RITA-3 trial demonstrated that the benefit of invasive treatment over conservative care continued to widen after the first year, demonstrating the greatest benefits in those in high-risk quartiles, with age being the strongest predictor of risk. ${ }^{23}$ 
A
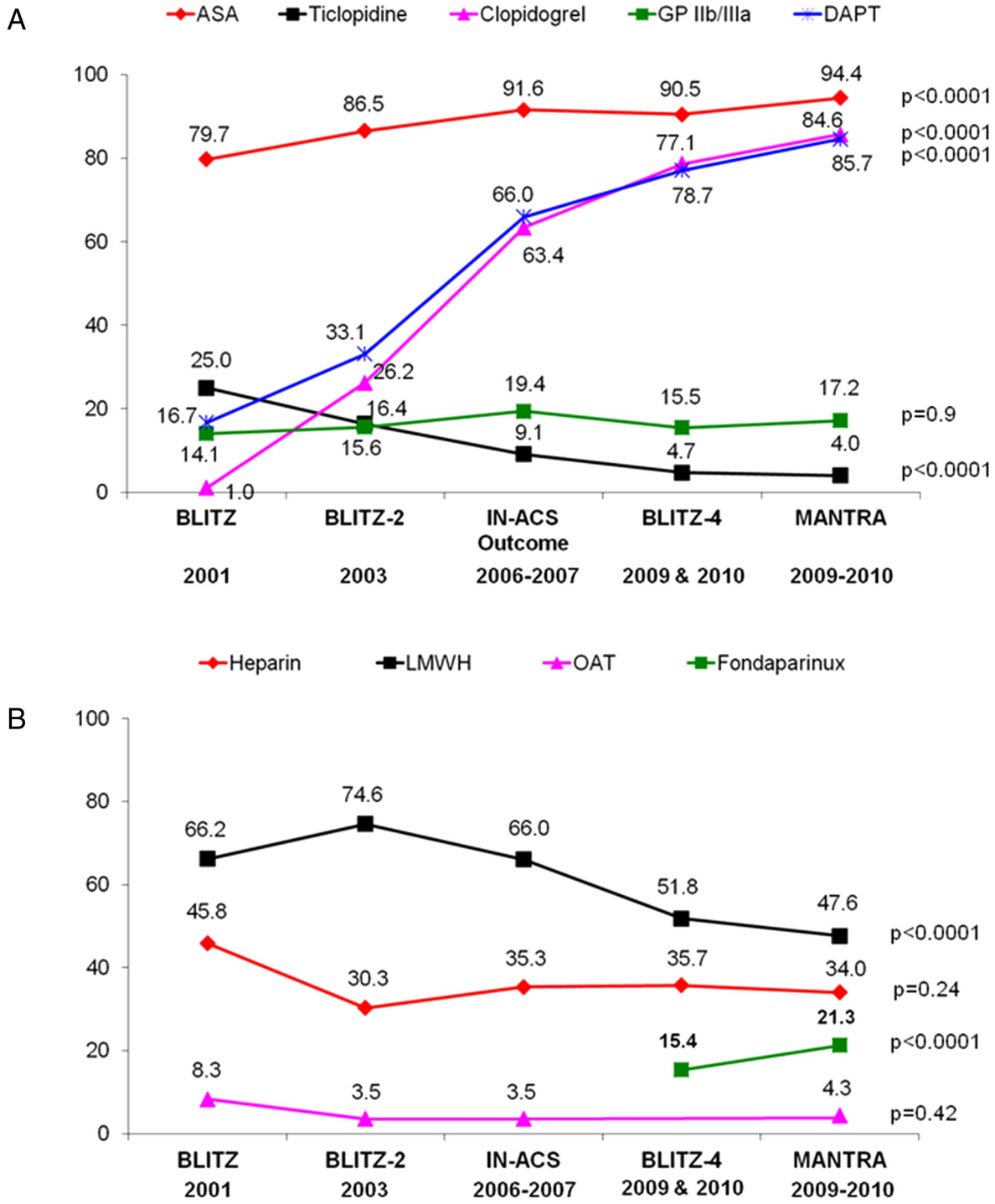

ASA: acetylsalicylic acid; DAPT: dual antiplatelet therapy; GPIlb/lla: glycoprotein IIb/lla receptor in hibitors; LMWH: Iow molecular weight heparin; OAT: oral anticoagulation therapy.

Figure 4 In-hospital use of antiplatelet agents (A) and anticoagulant drugs (B) in the decade of analysis.

Beyond mortality, all other outcomes did not present a significant trend over the decade, both during hospitalisation and at 30-day follow-up, with the exception of an increase in reinfarction during hospital stay, probably due to more accurate and sensitive diagnostic methods that have been recently developed. In this regard, it should be appreciated that the increasing accuracy of detecting NSTEMI developed over the years may have led to a selection of patients at lower risk and could partially explain the reduction in the rate of adverse events observed in our series.

Increased age is associated with an increased risk of drug-related adverse events, such as bleeding, frequently caused by excess dosing of antithrombolytic drugs. ${ }^{24}$ At variance with previous reports showing a high risk of major bleeding in elderly patients treated invasively (eg, $17 \%$ of patients $\geq 75$ years of age in the invasive arm of the TACTICS TIMI-18 trial) ${ }^{14}{ }^{15}$ the cumulative rate of major bleeding remained consistently low over time (approximately $2 \%$ at 1 month) in the Italian registries reported in this study, and consistently with the results of the recent Italian Elderly ACS study. ${ }^{7}$ This finding is most likely attributable to the moderate use of glycoprotein IIb/IIIa inhibitors, with a selective and decreasing use of low-molecular-weight heparin and with increasing use of the radial approach to PCI that accounts for approximately $35 \%$ in recent registries and as high as $70 \%$ in high-volume centres. ${ }^{7}$

\section{Limitations}

There are some limitations to our analysis. Although every effort was made in each survey to capture the greatest possible proportion of hospitals with CCU in the entire country, the ratio between the invited and 
Figure 5 Drugs prescribed from 2001 to 2010 in elderly patients discharged alive.

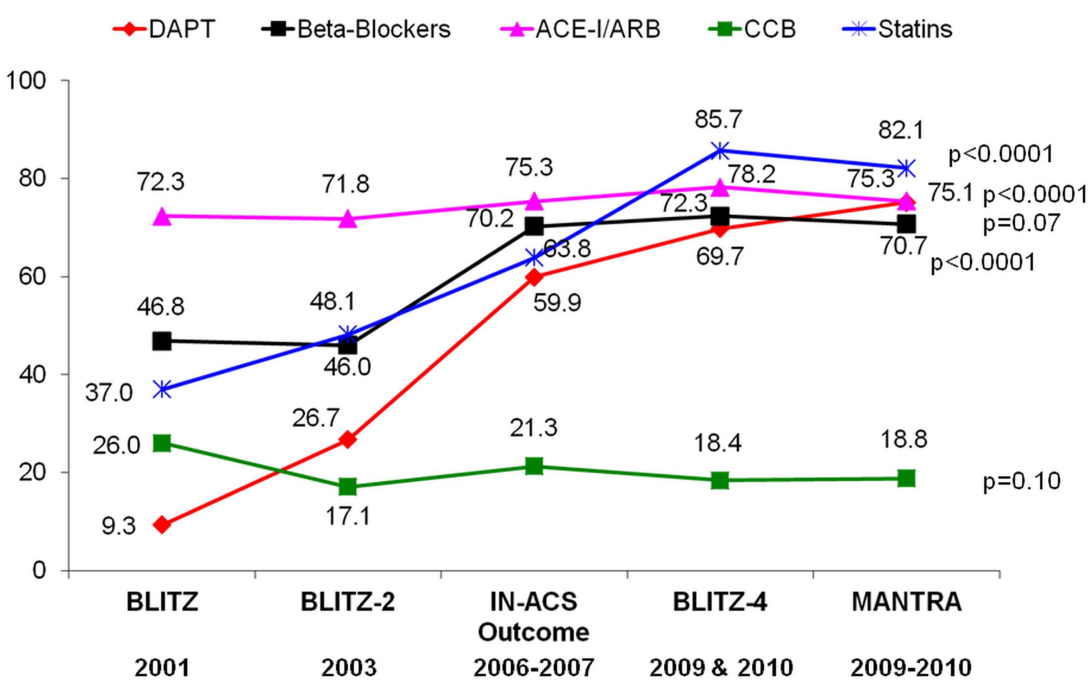

ACE-I/ARB an giotensin converting enzyme inhibitorslan giotensin receptor blockers; $C$ CB: Calcium channel blockers; DAPT: dual antiplatelet therapy

Table 3 In-hospital and 30-day clinical events of elderly patients admitted with NSTEMl from 2001 to 2010

\begin{tabular}{|c|c|c|c|c|c|c|}
\hline & $\begin{array}{l}\text { BLITZ, } \\
2001 \\
n=192\end{array}$ & $\begin{array}{l}\text { BLITZ-2, } \\
2003 \\
n=347\end{array}$ & $\begin{array}{l}\text { IN-ACS } \\
\text { OUTCOME, } \\
2006-2007 \\
\mathrm{n}=923\end{array}$ & $\begin{array}{l}\text { BLITZ-4, } \\
2009 \& 2010 \\
n=1941\end{array}$ & $\begin{array}{l}\text { MANTRA, } \\
2009-2010 \\
\mathrm{n}=947\end{array}$ & $\begin{array}{l}p \text { for } \\
\text { trend }\end{array}$ \\
\hline \multicolumn{7}{|c|}{ In-hospital events, n (\%) } \\
\hline Death & $19(9.9)$ & $13(3.8)$ & $40(4.3)$ & $81(4.2)$ & $63(6.7)$ & 0.90 \\
\hline Heart failure & 62 (32.3) & $25(7.2)$ & $137(14.8)$ & $370(19.1)$ & $165(17.4)$ & 0.72 \\
\hline Reinfarction & $3(1.6)$ & $1(0.3)$ & $19(2.1)$ & $27(1.4)$ & $28(3.0)$ & 0.02 \\
\hline Stroke & $2(1.0)$ & $2(0.6)$ & $10(1.1)$ & $15(0.8)$ & $10(1.1)$ & 0.86 \\
\hline Major bleeding & $4(2.1)$ & $8(2.3)$ & $9(1.0)$ & $58(3.0)$ & $17(1.8)$ & 0.45 \\
\hline \multicolumn{7}{|c|}{ 30-day events, n (\%) } \\
\hline Death & $28(14.6)$ & $26(7.5)$ & $65(7.0)$ & $121(6.2)$ & $90(9.5)$ & 0.36 \\
\hline Heart failure & 65 (33.9) & $35(10.1)$ & $141(15.3)$ & $378(19.5)$ & $177(18.7)$ & 0.97 \\
\hline Reinfarction & $8(4.2)$ & $13(3.8)$ & $27(2.9)$ & $31(1.6)$ & $34(3.6)$ & 0.33 \\
\hline Stroke & $5(2.6)$ & $4(1.2)$ & $11(1.2)$ & $19(1.0)$ & $13(1.4)$ & 0.41 \\
\hline Major bleeding & $4(2.1)$ & $8(2.3)$ & $11(1.2)$ & $60(3.1)$ & $20(2.1)$ & 0.31 \\
\hline
\end{tabular}

NSTEMI, non-ST elevation myocardial infarction;

\begin{tabular}{|c|c|c|c|c|c|c|}
\hline Study, year & N. events/pts & $\begin{array}{c}\text { 30-day } \\
\text { observed death } \\
\%(95 \% \mathrm{Cl})\end{array}$ & $\begin{array}{c}\text { 30-day } \\
\text { standardized death } \\
\%(95 \% \mathrm{Cl})\end{array}$ & $\begin{array}{l}\text { multivariable } \\
\text { logistic regression analysis }\end{array}$ & $\begin{array}{l}\text { A djusted }{ }^{\#} \\
\text { OR }(95 \% \mathrm{Cl})\end{array}$ & $p$ value \\
\hline BLITZ, 2001 & $28 / 192$ & $14.6(9.9-20.4)$ & $8.9(5.2-13.8)$ & reference & 1 & - \\
\hline BLITZ-2, 2003 & $26 / 347$ & $7.5(5.0-10.8)$ & $7.8(5.2-11.1)$ & & $0.52(0.28-0.96)$ & 0.04 \\
\hline IN-ACS, 2006-07 & $65 / 923$ & $7.0(5.5-8.9)$ & $8.8(7.0-10.8)$ & & $0.43(0.26-0.72)$ & 0.001 \\
\hline BLITZ-4, 2009\&10 & $121 / 1941$ & $6.2(5.2-7.4)$ & $9.7(8.4-11.1)$ & & $0.34(0.21-0.56)$ & $<0.0001$ \\
\hline MANTRA, 2009-10 & $90 / 947$ & $9.5(7.7-11.6)$ & $9.5(7.7-11.6)$ & & $0.55(0.33-0.92)$ & 0.02 \\
\hline
\end{tabular}

\#Multivariate logistic regression an alysis adju sted for gen der, age, systolic blood pressure, heart rate, diabetes, history of heart failure, prior stroke/TIA, peripheral artery disease, renal dysfunction, Killip class, atrial fibrillation, type of stu dy.

OR: odds ratio: Cl: confidence interval.

Figure 6 Observed and standardised all-cause mortality at 30 days. 
participating centres varies across registries from 0.7 to 0.3 . However, the geographical distribution and the availability of facilities of CCUs participating in different registries may be considered representative of the entire country. The duration of the surveys, clinical end points and programmed follow-up visits were not homogeneous. The short duration of follow-up (1 month) might have led to an underestimation of the benefits of implementation of care in terms of clinical events. In addition, the lack of central event adjudication might have amended the actual rate of adverse clinical outcomes.

We did not record specific contraindications to any medication; in an elderly population, this may have influenced the rate of use of certain drugs, and may have been an unrecognised confounder, but we would not expect the prevalence of contraindications to specific therapies, particularly antithrombotic therapies, to change markedly with time. In addition, we did not collect some variables such as frailty and functional status that are particularly important in elderly patients. Finally, analysing only patients admitted to CCUs may imply a selection bias.

\section{CONCLUSIONS}

In the past decade, substantial changes have occurred in the clinical characteristics and management of elderly patients admitted with a diagnosis of NSTEMI in Italian CCUs. We observed a marked increase in the use of recommended interventional and pharmacological strategies, including antithrombotic drugs used during hospitalisation and life-saving therapies prescribed at discharge, and these changes have been associated with a reduction in the adjusted early mortality rate.

\author{
Author affiliations \\ ${ }^{1}$ Department of Cardiovascular Sciences, European Hospital, Rome, Italy \\ 2Department of Cardiology, Ca' Foncello Hospital, Treviso, Italy \\ ${ }^{3}$ Cardiovascular and Neurologic Department, San Donato Hospital, Arezzo, \\ Italy \\ ${ }^{4}$ ANMCO Research Center, Florence, Italy \\ ${ }^{5}$ Division of Cardiology, Ospedale San Antonio Abate, Tolmezzo, Italy \\ ${ }^{6}$ Department of Cardiology, Maggiore Hospital, Bologna, Italy \\ ${ }^{7}$ Division of Cardiology, IRCCS Ospedale S. Martino, Genova, Italy \\ ${ }^{8}$ Department of Cardiovascular Diseases, S. Giovanni-Addolorata Hospital, \\ Rome, Italy \\ ${ }^{9}$ Cardiology Division, Campo di Marte Hospital, Lucca, Italy \\ ${ }^{10}$ Division of Cardiology, Ospedale A. Manzoni, Lecco, Italy
}

Acknowledgements The authors thank all the patients and investigators from all participating centres of the studies, as well as dedicated staff from the ANMCO Research Center.

Contributors DL and SS participated in the conception, design and conduct of the studies' analysis, drafted and revised the paper. DL and LG statistically analysed the data and revised the final manuscript. ZO, FC, AB and GDP were the principal investigators of the individual studies and made a critical revision of the final manuscript. $\mathrm{LB}, \mathrm{ADC}, \mathrm{GC}$ and FMB made a critical revision of the final manuscript.

Funding The studies included in this manuscript were funded by unrestricted grants as follows: BLITZ (Boehringer Ingelheim, Italy), BLITZ-2 (Merck, Sharp\&Dohme, Italy), IN-ACS Outcome (Sanofi-Aventis and Bristol-Myers Squibb, Italy), BLITZ-4 (Merck, Sharp\&Dohme, Italy) and MANTRA (Glaxo SmithKline, Italy). The sponsor of the studies was the Heart Care Foundation, a non-profit independent institution which is also the owner of the databases. Database management and quality control of the data were under the responsibility of the Research Centre of the Italian Association of Hospital Cardiologists (ANMCO). The Steering Committees of the studies had full access to all of the data in the studies and take complete responsibility for the integrity of the data and the accuracy of the data analysis.

Competing interests DL and LG, employees of Heart Care Foundation which conducted the studies, report Institutional grants from Glaxo SmithKline, Italy and grants from Merck, Sharp\&Dohme, Italy outside the submitted work. SS reports grants and personal fees from ELI LILLY, grants from NOVARTIS, grants and personal fees from IROKO, and personal fees from DAIICHI SANKYO, ROCHE, BAYER and ASTRA ZENECA outside the submitted work.

Ethics approval Local Italian Institutional Review Boards (IRBs).

Provenance and peer review Not commissioned; externally peer reviewed.

Data sharing statement No additional data are available.

Open Access This is an Open Access article distributed in accordance with the Creative Commons Attribution Non Commercial (CC BY-NC 4.0) license, which permits others to distribute, remix, adapt, build upon this work noncommercially, and license their derivative works on different terms, provided the original work is properly cited and the use is non-commercial. See: http:// creativecommons.org/licenses/by-nc/4.0/

\section{REFERENCES}

1. Fox KA, Steg PG, Eagle KA, et al.; GRACE Investigators. Decline in rates of death and heart failure in acute coronary syndromes, 19992006. JAMA 2007;297:1892-900.

2. Puymirat E, Simon T, Steg PG, et al.; for the USIK USIC 2000 and FAST MI Investigators. Association of changes in clinical characteristics and management with improvement in survival among patients with ST-elevation myocardial infarction. JAMA 2012;308:998-1006.

3. Rosengren A, Wallentin L, Gitt AK, et al. Sex, age and clinical presentation of acute coronary syndromes. Eur Heart $J$ 2004;25:663-70.

4. Rosengren A, Wallentin L, Simoons M, et al. Age, clinical presentation, and outcome of acute coronary syndromes in the Euroheart acute coronary syndrome survey. Eur Heart $J$ 2006;27:789-95.

5. Smith LG, Herlitz J, Karlsson T, et al. International comparison of treatment and long-term outcomes for acute myocardial infarction in the elderly: Minneapolis/St. Paul, MN, USA and Goteborg, Sweden. Eur Heart J 2013;34:3191-7.

6. Koopman C, Vaartjes I, Heintjes EM, et al. Persisting gender differences and attenuating age differences in cardiovascular drug use for prevention and treatment of coronary heart disease, 19982010. Eur Heart J 2013;34:3198-205.

7. Savonitto S, Cavallini C, Petronio AS, et al.; Italian Elderly ACS Trial Investigators. Early aggressive versus initially conservative treatment in elderly patients with non-ST-segment elevation acute coronary syndrome: a randomized controlled trial. JACC Cardiovasc Interv 2012;5:906-16.

8. Damman P, Clayton T, Wallentin L, et al. Effects of age on long-term outcomes after a routine invasive or selective invasive strategy in patients presenting with non-ST segment elevation acute coronary syndromes: a collaborative analysis of individual data from the FRISC II-ICTUS-RITA-3 (FIR) trials. Heart 2012;98:207-13.

9. Di Chiara A, Chiarella F, Savonitto S, et al.; BLITZ Investigators. Epidemiology of acute myocardial infarction in the Italian CCU network: the BLITZ study. Eur Heart J 2003;24:1616-29.

10. Di Chiara A, Fresco C, Savonitto S, et al.; BLITZ-2 Investigators. Epidemiology of non-ST elevation acute coronary syndromes in the Italian cardiology network: the BLITZ-2 study. Eur Heart J 2006;27:393-405.

11. Rizzello V, Lucci D, Maggioni AP, et al.; IN-ACS Outcome Investigators. Clinical epidemiology, management and outcome of acute coronary syndromes in the Italian network on acute coronary syndromes (IN-ACS Outcome study). Acute Card Care 2012;14:71-80.

12. Olivari Z, Steffenino G, Savonitto $S$, et al. The management of acute myocardial infarction in the cardiological intensive care units in Italy: the 'BLITZ 4 Qualità' campaign for performance measurement and quality improvement. Eur Heart $J$ Acute Cardiovasc Care 2012;1:143-52. 
13. Casella G, Di Pasquale G, Oltrona Visconti L, et al. Management of patients with acute coronary syndromes in real-world practice in Italy: an outcome research study focused on the use of ANTithRombotic Agents: the MANTRA registry. Eur Heart $J$ Acute Cardiovasc Care 2013;2:27-34.

14. Rao AK, Pratt C, Berke A, et al. Thrombolysis In Myocardial Infarction (TIMI) Trial-Phase I: haemorrhagic manifestations and changes in plasma fibrinogen and the fibrinolytic system in patients treated with recombinant tissue plasminogen activator and streptokinase. J Am Coll Cardiol 1988:11:1-11.

15. Alexander KP, Newby LK, Cannon CP, et al.; American Heart Association Council on Clinical Cardiology; Society of Geriatric Cardiology. Acute coronary care in the elderly, part I: non-ST-segment-elevation acute coronary syndromes: a scientific statement for healthcare professionals from the American Heart Association Council on Clinical Cardiology: in collaboration with the Society of Geriatric Cardiology. Circulation 2007;115:2549-69.

16. Bach RG, Cannon CP, Weintraub WS, et al. The effect of routine, early invasive management on outcome for elderly patients with non-ST-segment elevation acute coronary syndromes. Ann Intern Med 2004:141:186-95.

17. Angeli F, Verdecchia P, Savonitto S, et al. Early invasive versus selectively invasive strategy in patients with non-ST-segment elevation acute coronary syndrome. impact of age. Catheter Cardiovasc Interv 2014;83:686-701.
18. Elbarouni B, Ismaeil N, Yan RT, et al. Temporal changes in the management and outcome of Canadian diabetic patients hospitalized for non-ST-elevation acute coronary syndromes. Am Heart J 2011:162:347-55.

19. Schiele F, Meneveau N, Seronde MF, et al.; on behalf of the 'Reseau de Cardiologie de Franche Comte'. Changes in management of elderly patients with myocardial infarction. Eur Heart J 2009;30:987-94.

20. Stone PH, Thompson B, Anderson HV, et al.; for the TIMI III Registry Study Group. Influence of race, sex and age on the management both unstable angina and non-Q-wave myocardial infarction: the TIMI IIII Registry. JAMA 1996;275:1104-12.

21. Roe MT, Li S, Thomas L, et al. Long-term outcomes after invasive management for older patients with non-ST-segment elevation myocardial infarction. Circ Cardiovasc Qual Outcomes 2013;6:323-2.

22. Morici N, Savonitto S, Murena E, et al. Causes of death in patients $\geq 75$ years of age with non-ST-segment elevation acute coronary syndrome. Am J Cardiol 2013;112:1-7.

23. Fox KA, Poole-Wilson P, Clayton TC, et al. 5-Year outcome of an interventional strategy in non-ST-elevation acute coronary syndrome: the British Heart Foundation RITA-3 randomised trial. Lancet 2005;366:914-20.

24. Alexander KP, Chen AY, Roe MT, et al.; CRUSADE Investigators. Excess dosing of antiplatelet and antithrombin agents in the treatment of non-ST-segment elevation acute coronary syndromes. JAMA 2005;294:3108-16. 